\title{
In Praise of Civicide
}

\author{
P. A. Hancock
}

\section{Synopsis}

Resolving our current, human-generated (iatrogenic) problems must go beyond the search for purely technical remediations to embrace a re-casting of our fundamental forms of human social organizations and behavior. These designed innovations, representing mindful applications of biomimetic principles, can serve to help steer humankind toward a path of possible sustained, civilized survival and away from our current track of incipient social destruction.

\section{Introduction}

There can be little doubt that the current path of collective human progress is profoundly paradoxical. On the one hand human beings laud technology as the primary conduit of progress. On the other, the human race surely realizes that many of technology's material expressions, such as global warming, represent imminent existential threats [7]. We persist with this sociotechnical schizophrenia and ever-compound the problem by seeing our future salvation almost exclusively in terms of technological resolutions. This flawed logic assumes that because technology has served to create the current bind we find ourselves in, then we must necessarily require technological solutions to resolve it. On the surface, this strategy appears to make some sense. After all, what other viable ways do we actually possess in order to alter our collective future? But there is another way and we must recognize and exploit it before it is too late; if it is not too late already.

Since the first expression of the Malthusian nightmare it is apparent that we cannot continue our unbound consumption and subsequent dismissal of necessarily limited physical resources without consequence [30, 36]. Despite laudable efforts at recycling and re-purposing, ultimately there's is a finite supply and any social system

\footnotetext{
Correspondence: peter.hancock@ucf.edu
}

The present title stands in large part as homage to the vital and still relevant Essay of Desiderius Erasmus, "In Praise of Folly." [10]. In searching to praise itself but ending on the road to chaos, the folly that Erasmus identifies recapitulates the hubris of our own present technological age. Thus, Erasmus's cautionary tale very much remains a lesson for our own times. Department of Psychology, and Institute for Simulation and Training, University of Central Florida, Orlando, FL 32826, USA that envisages a continuing vista of unlimited 'growth' in order to support evermore chimerical 'profit' in the name of putative 'progress,' is doomed to failure. In its essence, as Shakespeare wrote about unsatisfied desire, "... all this the world well knows, yet none knows well; to shun the heaven that leads men to this hell." And so this recipe for disaster and the ultimate demise of civilization has not escaped important and repeatedly critical attention (see e.g., [31, 35]). Although some individuals optimistically envisage and tout a world of limitless free energy, at some juncture, the piper has to be paid. And that ominous musician has now come to demand his tariff. Symptoms of this discontent and dysfunctionality are everywhere about us in the form of diminished and severed closed-loop feedback and feed-forward systems which subsume the evident instabilities in the very planetary infrastructure that supports all of life (for local effects see [18], and more contentiously, see [29]). Yet successive generations, each necessarily born into their own window of ignorance, continue to act as though his debt can be permanently postponed, or even better ignored. But now our whole planet is clearly emitting its own unmistakable set of warning signs. Often for parochial political reasons, these warnings continue to be discounted, or at least, on a collective basis, sufficiently ignored such that incipient disaster looms ever closer. What can we do to avert this forthcoming, self-induced collapse of human civilization; an eventuality I define as - civicide. As this is a new term, it is perhaps, at this juncture, worth explaining it in a little more detail. Civicide, the destruction of the fine cobwebs of advanced integrated, society-supporting technical systems is an immediately proximal concern. This is because I do not believe the human race will necessarily be victims of immediate and total extinction. Across the time of their existence, humans have proven to be a hardy, adaptive, and resilient species that can eek out survival in the most unlikely and hostile of places. I believe therefore, that the incipient existential threat is not to each and every individual member of the species. Rather, it is to the emergent ways in which humans have collectively organized themselves and, in consequence, prospered and dominated over the last ten to twenty millennia. It 
is the fragile skein of technologically-supported modern civilization that stands in greatest peril (and see [3]). It is to this level of organization that the evident iatrogenic dysfunctionality provides the greatest degree of threat. Thus the specific term refers to the suicide of civilization, or 'civicide.'

We are not the first, although we may be close to being the last, generation to recognize the urgency of the approaching catastrophic failure of the natural global regulatory system (cf., [28, 29]). Typically, modern-day projections are founded upon predictions derived from the most sophisticated computer models available at the time when such doom is foretold. These forecasts prove to be more or less accurate as all such projections necessarily must be, since they are contingent upon models which by definition must be a reduced representation of the full system under scrutiny (e.g., [4]). However, when precise prediction falls short of experienced reality, those in greater society with the propensity to do so, take such variance, not as evidence of the obligatory shortfall intrinsic to models themselves, but rather as prima facie evidence of absolute predictive failure. Associated scientific statements are now capable of being dismissed with pabula such as 'scientists just don't know what they're talking about.' Palliative political pronouncements are then produced to justify and sustain the status quo. And these latter political expressions always represent powerful forces of inertia since, for many such commentators, the status quo is apparently just fine (but see [2]). However, eventually the necessary evolution of any status quo, that some protest is unchanging, will almost certainly, prove unsustainable. Each of the immediate past generations has managed to postpone that evil day. But the evil day is now squarely upon us.

There are two fundamental driving forces which promote civicide. They are population numbers and resource utilization rate (and see [5]). With respect to the former, human numbers proliferate alarmingly, as prior predictions such as that advanced by Ehrlich have been confirmed [9]. The step from one billion people in 1800 to three billion in 1960 took 160 years. The emergence of the next increase of two billion took less than 30 years. Even a brief perusal of any world population growth chart shows evidence of intrinsic and even terminal, positive feedback influences (see Fig. 1 and see [39]). Although this absolute rate of increase is not quite as spectacular as was at one time feared we have, in disturbing observations, seen how projections as to world population at some specified future date (e.g., 2020) have each been sequentially revised upward as we approach the actual date. That is, we see a consistent underestimation of population numbers which gets sequentially revised upwards as the actual date approaches. Today there, are more individuals alive than have ever

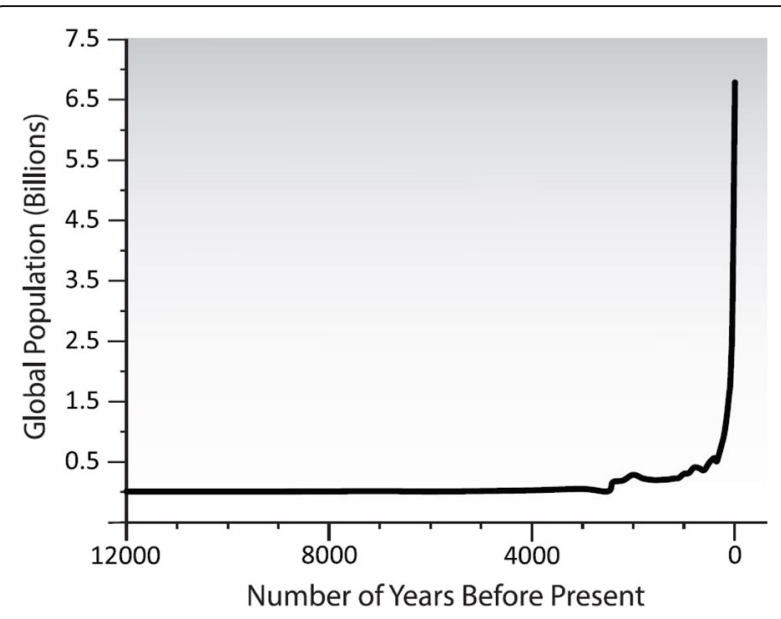

Fig. 1 Standard, simple iconic image of the growth of world human population across the past twelve millennia. The graph shows a morphology redolent of a positive feedback system in operation

lived and passed on (i.e., the total number of people alive today exceeds all prior humans who have ever lived on this planet). This anticipated number of living individuals is more than our planet can reasonably sustain [40]. This is especially true in light of the second factor which is the rate of resource utilization. Theoretically, even one individual over-using the finite resources of any planet would be sufficient to induce disaster. However, our collective cognitive desires (as opposed to our actual corporeal needs) have pushed the global system beyond the edge of stability. The result is that we are now using up more planets than we actually have (Fig. 2, and see [38]).

Even this rate of resource use is not systemically 'neutral' because we not only use resources, we produce waste. Manufacturing processes which support the demands of

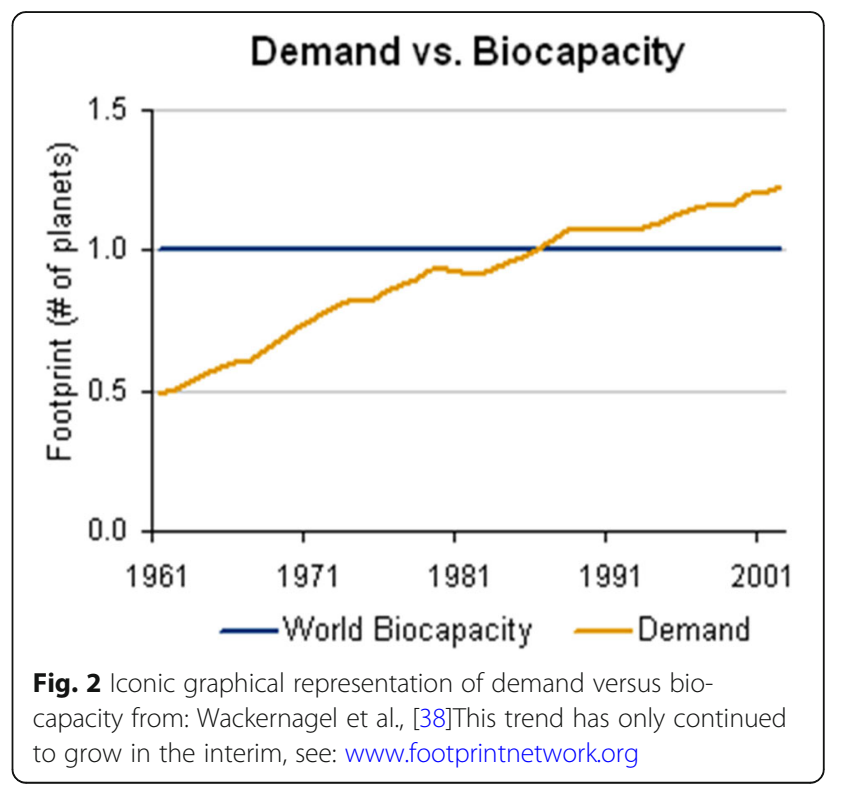




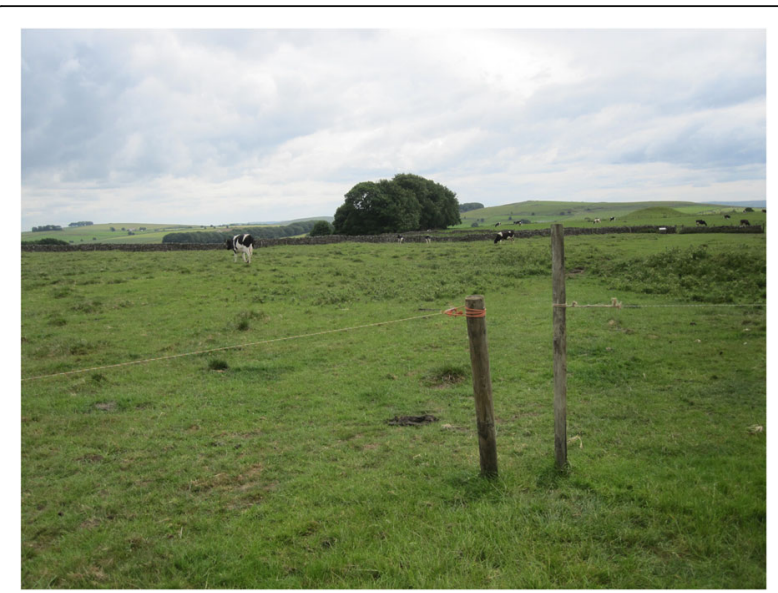

Fig. 3 This picture shows an effective barrier to the passage of the cows in the field who is deterred by the electric fence and the insufficient breadth of the opening between the wooden stakes. At the same time this same opening "affords" passage for human beings. The image is taken on the path between the pre-historic sites of Arbor Low and Gib Hill in Derbyshire England (Photograph by the Author)

contemporary civilization generate untenable amounts of this accumulative waste. Our planet is now intimately knitted together by informational networks and communications media of unprecedented power. This means that those beyond the so-called 'first' world have immediate and intrusive material impressions of what nominally connotes 'the good life.' Sadly, this expanding vision often equates quality of life with an ever greater accumulation of material possessions $[8,19]$. In short, more than seven billion people are now told that they should all want smart phones, large-screen TV's, high-powered vehicles and the latest gadget or gizmo which occupies contemporary collective consciousness. Short-cycle, profit-driven corporations, motivated by the emergently "invisible hand" of greed are determined to give it to them [37]. There arises then an invidious and largely illusory trade between induced, ephemeral desires (think of a child's demand for the latest Christmas toy) with the very real human needs for air, water and food. Today, the modal issue of immediate concern is iatrogenic global warming (see [33, 34]), which is most intimately related to the unbridled and continuing employment of fossil fuels (and see [22]). Such global warming (so cleverly morphed into the less threatening phrase climate change) exhibits all of the symptomatology of a system at a point of critical transition. As with the differentiation between adaptive and resilient systems (see [21]), the climate itself is 'ringing' out its warning in the form of ever greater oscillations of critical indicators. The transition epochs of many systems are characterized not only by a change in the mean level of these critical systemic indicators, but by a marked increase in their exhibited variability. Such oscillations (or 'ringing' as I have termed it) are harbingers of significant change. Problematically, this disturbance to the thermal climate also represents a significant threat to cognition, which we humans believe will serve to extract us from the incipient danger (see [26, 27]). So then, starved and dying of thirst we may still be able to post on Facebook just how bad things have gotten. Such is the bleak future that we face but whose more optimistic expression we continue to sell to ourselves. It is a global, psychological mind-set that foreshadows civicide as I have described it. But what of alternative futures? Can we use the manifest "visible" hand of intentional (teleological) design to resolve the conundrum of this collective psychological mindset [14]? The hopeful answer that we all wish to hear is; it may be possible.

One vital lens through which to view our present predicament is the most useful and effective perspective of cybernetics [18]. A fundamental theory of control, cybernetics (literally, steering principles) is associated with a legion of cross-disciplinary insights of the immediate post World War II era. Championed by a series of luminaries, but most especially by Norbert Wiener [39], cybernetics is a network science that describes and explains the influences involved in both integrated feedforward and feed-back loops (and see [1]). Such loops compose the functional architecture of both 'natural' and human societies. Most critically for our present circumstances, cybernetic principles help us to understand a crucial dilemma. This dilemma juxtaposes the search for local optimization of certain, proximal discrete systems against an evident degree of dysfunctionality at the summated level of the global system. So, for example, nations, corporations, regions, cultures and collectives of all kind are designed to optimize their own immediate prospects and environments. Yet as they achieve this, the global system appears, almost inevitably, to suffer. In this case local optimality opposes global sustainability. Whether this proximal optimality vs. global dysfunctionality relationship is a necessary attendant upon human progress is very much a theoretically debatable proposition. Its present expression in our own reality is not.

Some early theorists of human social interaction proposed an intrinsic control mechanism that regulates collective action, and I have already noted Smith's putative 'invisible hand' which became very corporeal in the financial meltdown of 2008. Although all models are necessarily reductions of real-world circumstances, our hopes have to lie in the effective and adequate modelling of such complex systems. Our current prognostications emerge from sophisticated models, yet necessarily it is a prohibitive task to try to model a system with so many interactive variables. However, in the same way that the world represents, for us humans, the terrestrial 'system of all systems,' so we need an aggregation of various 
appropriate models in order to fully represent what we aspire to predict. This would be, if you will, a 'model of all models.' It is unlikely that human scientists can provide a sufficiently integrative effort to derive this under the time horizon that appears available; however, this also is a debatable proposition. The evident solution to any such shortfall is the enactment of nascent 'autonomous' systems as directed to this work in order accomplish such predictive efforts. In such an enterprise, the emergent properties of individual autonomous entities are equated with some of the known critical dimensions e.g., climate, population, water shortage etc. Such avatars of these conceptual representations may then mutually engage in order to explore the spaces of possibility sustainability that emerge. Whether humans can or will consider or act upon what are liable to be quite radical outcome recommendations is, in my view, unlikely; others may be more sanguine about the proposition. The evident battle between the ego of the individual and the existential survival of the civilized collective, which such autonomous agents would have to engage in, may well curtail the freedoms that we prize so much in quite drastic ways. It may well specify a pathway to potential survival, at least of putatively civilized society, but at what costs? What will that society then look like and will it retain any resemblance to what we in western counties now experience? Yet, as individual human life is so relatively short and the travelling window of ignorance renews itself with each generation, it may be that such 'solutions' are accepted as the inevitable status quo (the new normal) within one or two generations at most. Viable solutions to limitations on human longevity would certainly temper any such strategies.

Our current, dominant global form of social organization is largely erected upon the principle of a nominally 'free' market. I do not dwell on a number of contemporary transgressions to this principle which, as I have noted, were inherent in the governmental responses to recent financial crises. However, I do note that those latter governmental actions do provide an important existence proof that, by both intention and by design, such social change proves feasible. Recognizing this possibility, I would suggest that resolution to the issues raised above may be embedded in a more general consideration of the uses of intentional design in determining our collective social purpose (and see [6]). In pure market environments, manufacturers propose and consumers dispose. A product is brought to market and its fate is decided by individuals who choose to, or choose not to participate via purchase. However, this assertion very much under-estimates the numerous dimensions of consumer behavior which influence both prospective considerations to buy as well as point-of-sale purchase decision-making. As Nobel-Prize winning scientist Daniel Kahneman has shown [24], one might choose to buy due to peer pressure, popularity, or effective marketing rather than simply as a result of some purportedly antiseptic and purely rational choice associated with the perceived utility of the item at hand. As any vendor understands, individuals rarely exercise emotionless choice but rather are affected by any number of personal, momentary influences. As we consider the overarching aim of civilization we need to use this understanding of how psychological decision processes influence choice at all levels of society. To change our present course then, we need to implement designed affordances which, by their design characteristics, naturally encourage and induce overall survival-oriented behavior (and see $[11,12])$. The term affordance here is a technical one that connotes an emergent relationship between a user and the technological ecology that surrounds them. An affordance exploits 'instinctive' human responses to the opportunity that such technology presents. The notion of an affordance is derived from the conceptual thinking of James Gibson (see e.g., [12]) and before him Kurt Lewin [25] and finds much modern expression in the sciences of Human Factors and Ergonomics (see e.g., [32]). Thus for example, a chair "affords" sitting in the same way that a door "affords" entry (think of trying to sit on a pointed stick, see e.g., the "Judas Cradle") or think of trying to pass through the window of a doll's house. Each of these latter examples are forms of negative affordance in which the specific form of behavior is discouraged. Figure 3 presents an example in which a landowner has created a human "passageway" (i.e. obviously affords passage for the human pedestrian) and yet this affordance denies the cows in the field any equivalent opportunity to pass beyond the electrified fence. Behavior in relation to such affordances often does not rise to the level of conscious cognition. Yet such implicit processing still provides vital constraints on outcome behavior.

To give a specific example of human affordance design, the management at Schiphol airport in Amsterdam reduced their maintenance costs by engraving an image of a fly on the urinals of the men's restroom. This designed affordance took advantage of men's intrinsic propensity to "aim" for a presented target during urination. Such designed change in that environment modified users behavior to reduce 'splashing' and therefore cleaning and maintenance costs. Importantly, it also created a degree of enjoyment that serves to sustain the desired behavior across time (and see [20]). On its face, this appears to be a rather trivial example. However, the applications of these self-same principles on a wider, and even global scale, are of much greater import. These principles, derived from an understanding of the fundamental psychology of decisions, can be called upon to support the present proposed contention of 'survival 
design' (see e.g., [23]). I suggest therefore, that such affordances should represent an imperative moral foundation for an intentional design for our collective future $[15,16]$. Such affordances are most emphatically not restricted to restrooms since they can guide the design of all the fundamental ways in which we organize ourselves as a global species. We can, and I would protest must, design so that individual and collective choices are steered toward survival as compared to the noted local optimization which courts disaster. Is this mindful design strategy beyond humankind to achieve? Or, will we remain mindless lackeys who passively accept whatever momentary, disaster-inducing technology is foisted upon us? In the same way that Grogan [13] poses this question in respect to biology, framed around the critical application of the principles of biomimesis, I am more persuaded that our answer can be found in our own psychology and its intimate relation to technology; an extension I have termed autobiomimesis (see [17]).

If we are to disengage from the unwelcome race between functional redundancy and existential persistence, civilized society must find a stable balance between resource utilization and resource recycling. We currently show no effective indications of achieving this resilient state of planet-wide equilibrium. But there is, as always another side, which is the antithesis to this quest for stability. For example, if we are able to abandon the hubris of the human state even for a moment, we might approach this from the perspective of the rest of life on the planet. Surely, as all other living organisms peruse the on-going machinations of one, tragically dominant species (to any degree that such living beings able to do so) their collective vote would surely be going against the human race. While the hardy and resilient cockroach may be looking forward to the banquet that will be the sequela of human civicide, many other species may well not survive to see that 'glorious' day (and see: http://billmckibben.com/; with respect to honeybees). If we were involved in some biota-based game of 'Survivor', it is rather clear we would have already been voted off the planet. Mindful collective design, which can be founded on perceptual affordance structures and the motivational maps of topological psychology, seems presently to be beyond a faction-riven, nationalistically-driven and corporatelymanipulated species. By the time any such a considered strategy is countenanced and enacted it will, almost certainly, be far too late (and perhaps already is). I believe it is rational to now conclude, and state, that for human civilization, the game is up. As I have said, I do not believe our coming, albeit relatively slow-moving cataclysm, will immediately destroy all human beings - we are much too hardy, adaptable, and resilient a species for that. What is in danger of most immediately dissolving is the fragile skein of civilization; the empirical Anthropocene experiment. It is also clear that the end-state incarnations of such a selfinduced, iatrogenic civicide will not be pretty. While I am sure there will still be people around, and some may even be able to read this, it will be small comfort to them, and none to me.

\section{Summary}

An earlier commentator on this essay believed that the title itself was a call for mass extermination. Far from it. In the same way that Erasmus turned the mirror of satire upon his own times, I seek to use the same rhetorical device in discussing the ways that we meet the demons of our own age. And yet within the satire lies elements of undeniable truth. We are on an evident path to destruction and its pursuit, on a global scale is surely folly. Rather than the mindless, or at best ad hoc approaches to what passes for progress, we surely now need a purpose-directed stabilization of the socio-technical system of all systems (our world). This requires us to embrace a rational and purposive design of human intentions, aspirations, goals and morality into our technologies as much it does the technical features of the complex operational systems which underpin our individual and social goals.

\section{Acknowledgments \\ The author would like to thank the Editor and Reviewer for helpful and insightful comments on a previous version of the present work. Figure 1 is drawn from: \\ (https://images.search.yahoo.com/yhs/search?p=human+population+by+ year\&fr $=y$ hsmozilla004\&hspart $=$ mozilla\&hsimp $=y$ hs004\&imgurl $=h t t p s \% 3 \mathrm{~A} \% 2$ F\%2Fupload.wikimedia.org\%2Fwikipedia\%2Fen\%2F3\%2F3a\%2FHuman_ population_growth_from_1800_to_2000.png\#id $=13 \& i u r l=h t t p \% 3 A \% 2 F \% 2$ Fwww.cambridgeblog.org\%2Fwpcontent\%2Fuploads\%2F2017\%2F04\%2Ffig-3. jpg\&action $=$ click)}

\section{Authors' contributions}

The author read and approved the final manuscript.

\section{Authors' information}

Peter Hancock is Provost Distinguished Research Professor, Pegasus Professor and University Trustee Chair in the Department of Psychology and the Institute for Simulation and Training at the University of Central Florida in Orlando, Florida. He is a Fellow of ten scientific research societies including the American Association for the Advancement of Science (AAAS) and the Institute of Electrical and Electronic Engineers (IEEE). He is a Fellow and past president of the Human Factors and Ergonomics Society, as well as the Society for Engineering Psychology. His work focuses on human-technology relationships and the possible futures of this symbiosis.

\section{Competing interests}

The author declares that they have no competing interests.

Received: 15 March 2019 Accepted: 14 October 2019

Published online: 11 December 2019

\section{References}

1. Beer S. The will of the people. J Oper Res Soc. 1983:34(8):797-810.

2. Chin G, Culotta $E$. The science of inequality: what the numbers tell us. Science. 2014;344:819-21 and see whole section.

3. Clark K. Civilisation. London: John Murray; 1969.

4. Club of Rome. The predicament of mankind: Quest for structured responses to growing world-wide complexities and uncertainties. (see: Meadows, D. 
(1974). The limits to growth; a report for the club of Rome's project on the predicament of mankind). New York: Universe Books; 1970.

5. Cohen JE. Population growth and earth's human carrying capacity. Science. 1995;269:341-6.

6. Dekker SWA, Hancock PA, Wilkin P. Ergonomics and the humanities: ethically engineering sustainable systems. Ergonomics. 2013:56(3):357-64.

7. Drury CC. Can HF/E professionals contribute to climate change solutions? Ergon Des. 2014;22:30-3.

8. Drury C, Hancock PA. For a sustainable world what should HF/E optimize? In: Thatcher A, Zink K, Fischer, editors. Human Factors for Sustainability: Theoretical Perspectives and Global Applications. Boca Raton: CRC press; 2019. p. 35-50.

9. Ehrlich PR. The population bomb. New York: Ballantine Books; 1968.

10. Erasmus, D. (1509). In praise of folly. (retrieved from: http://www.gutenberg. org/files/30201/30201.txt).

11. Flach JM, Voorhorst F. What matters? Dayton: Wright State University; 2014.

12. Gibson JJ. The ecological approach to visual perception. Boston: Houghton Mifflin; 1979.

13. Grogan P. Our anthropocene future: what biology can tell us. Free Inquiry. 2013;33(2):16-9.

14. Hancock PA. Teleology for technology. In: Parasuraman R, Mouloua M, editors. Automation and human performance: theory and applications. Hillsdale: Erlbaum; 1996. p. 461-97.

15. Hancock PA. Mind, machine and morality. Chichester: Ashgate; 2009

16. Hancock PA. Ergaianomics: the moral obligation and global application of our science. Ergonomist. 2012;503:12-4.

17. Hancock PA. Autobiomimesis and our way ahead. Daventry: Paper presented at the annual conference of the chartered Institute of Ergonomics and Human Factors; 2015.

18. Hancock PA. The humane use of human beings. Appl Ergon. 2018;79:91-7.

19. Hancock PA, Drury CG. Does human factors/ergonomics contribute to the quality of life? Theor Iss Ergon Sci. 2011;12:1-11.

20. Hancock PA, Pepe A, Murphy LL. Hedonomics: the power of positive and pleasurable ergonomics. Ergon Des. 2005;13(1):8-14.

21. Hoffman RR, Hancock PA. Measuring resilience. Hum Factors. 2017;59(4): $564-81$

22. The Intergovernmental Panel on Climate Change (2019). Synthesis Report: Climate Change 2022. www.ipcc.ch/report/sixth-assessment-report-cycle.

23. Ismail SO, Ojolo SJ, Orisaleye Jl, Alogbo AO. Design and development of a dual solar water purifier. Int J Adv Sci Eng Technol Res. 2013;2(1):8-17.

24. Kahneman D. Thinking, fast and slow. New York: Farrar, Straus \& Giroux; 2011

25. Lewin K. Principles of topological psychology. New York: McGraw-hill, (read books, 2013); 1936.

26. Lopez-Sanchez II, Hancock PA. Thermal effects on cognition: a new quantitative synthesis. Int J Hyperth. 2018;34(4):423-31.

27. López-Sánchez Jl, Hancock PA. Diminished thinking capacity in an everhotter world: evidence from an applicable power-law description. Hum Factors. 2019;61(6):906-19.

28. Lovelock J. Gaia: a new look at life on earth. Oxford: Oxford University Press; 2000.

29. Lovelock J. The revenge of Gaia. London: Penguin; 2006.

30. Malthus TR. An essay on the principle of population. London: J. Johnson; 1798.

31. McKibben B. Enough: staying human in an engineered age. New York: Henry Holt; 2004.

32. Moray N. Ergonomics and the global problems of the twenty-first century. Ergonomics. 1995;38(8):1691-707.

33. Nickerson RS. Is global warming a challenge to human factors/ergonomics? Ergon Design. 2014;22:4-7.

34. Pacala S, Socolow R. Stabilization wedges: solving the climate problem for the next 50 years with current technologies. Science. 2004;305:968-72.

35. Scranton R. Learning to Die in the Anthropocene: Reflections on the End of a civilization. San Francisco: City Lights Publishers; 2015.

36. Seidl I, Tisdell CA. Carrying capacity reconsidered: from Malthus' population theory to cultural carrying capacity. Ecol Econ. 1998:31(3):395-408.

37. Smith $A$. An inquiry into the nature and causes of the wealth of nations. London: W. Strahan and T. Cadell; 1776.

38. Wackernagel M, Schulz NB, Deumling D, Linares AC, Jenkins M, Kapos V, Monfreda C, Loh J, Myers N, Norgaard R, Randers J. Tracking the ecological overshoot of the human economy. Proc Natl Acad Sci. 2002;99(14):9266-71.
39. Wiener N. The human use of human beings. New York: Houghton-Mifflin; 1950

40. Wilson EO. The future of life. New York: Knopf; 2002.

\section{Publisher's Note}

Springer Nature remains neutral with regard to jurisdictional claims in published maps and institutional affiliations.
Ready to submit your research? Choose BMC and benefit from:

- fast, convenient online submission

- thorough peer review by experienced researchers in your field

- rapid publication on acceptance

- support for research data, including large and complex data types

- gold Open Access which fosters wider collaboration and increased citations

- maximum visibility for your research: over $100 \mathrm{M}$ website views per year

At $\mathrm{BMC}$, research is always in progress.

Learn more biomedcentral.com/submissions 